\title{
Assessment of consistency in the dimension of gutta-percha cones of ProTaper Next and WaveOne with their corresponding number files
}

\author{
Nitika Bajaj ${ }^{1}$, Prashant Monga ${ }^{2}$, Pardeep Mahajan²
}

Correspondence: Dr. Prashant Monga

Email: artdaentalstudy@yahoo.co.in

\author{
'Department of Pedodontics and Preventive Dentistry, \\ Dasmesh Institute of Research and Dental Science, \\ Faridkot, Punjab, India, \\ ${ }^{2}$ Department of Conservative Dentistry and \\ Endodontics, Genesis Institute of Dental Sciences and \\ Research, Ferozepur, Punjab, India
}

\section{ABSTRACT}

Objectives: To compare the dimensions of gutta-percha (GP) cones of ProTaper Next (25/0.06) and WaveOne (25/0.08) in relation to their corresponding instruments of the same dimension, respectively. Materials and Methods: Two groups of GP cones were made with 25 cones in each group. Group 1 consisted of 25 GP cones \# 25/0.06 (ProTaper Next). Group 2 consisted of 25 GP cones \# 25/0.08 (WaveOne). Measurements were done at D1 (1 mm short of the tip), D3 (3 mm short of the tip), and D11 (11 mm short of the tip) for GP cones of both groups and were compared with their corresponding instruments. Results: Group 1 (ProTaper) 25/.06 GP points showed greater diameters than those of the corresponding instrument, which was statistically significant. Group 2 (WaveOne) 25/0.08 GP points showed greater diameters than those of the corresponding instrument which was statistically significant whereas it was nonsignificant at level D1. Conclusion: Diameters of both ProTaper Next and WaveOne GP cones were greater than their corresponding instruments. Hence, there are chances of under obturation with both systems.

Key words: Gutta-percha, obturation, ProTaper Next, WaveOne

\section{INTRODUCTION}

Three-dimensional obturations is one of the main objectives of root canal treatment. ${ }^{[1]}$ Hence, to achieve this objective, adequate adaptation of gutta-percha (GP) filling to the canal walls is mandatory. ${ }^{[2]}$

When GP is used for root canal obturation as solid core material, some minor gaps are commonly left between GP and root canal walls. To fill these gaps and form fluid tight seal, some form of sealer is used. However, these sealers may be a source of microleakage and should be used in minimal amount. ${ }^{[3]}$ To minimize the

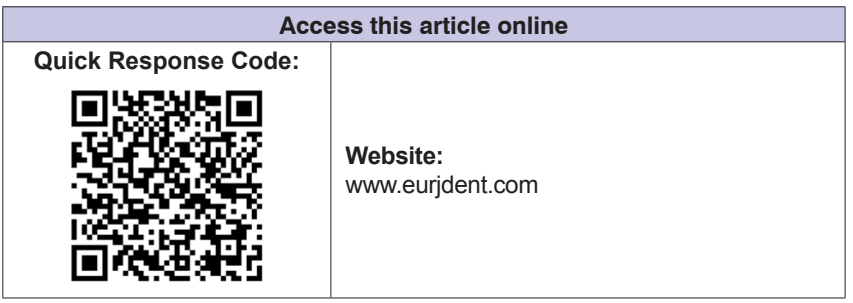

amount of sealer, dimension of master GP cone should closely match the dimension (diameter and taper) of the last instrument used at working length. This compatibility of dimension will lead to adaptation of GP cone to canal wall, thus leaving a minimal space for sealer. ${ }^{[4]}$ This is particularly important when we are using single file system with corresponding standardized greater taper single GP cone for obturation. For single GP cone obturation technique, standardization of cone is very important.

This is an open access article distributed under the terms of the Creative Commons Attribution-NonCommercial-ShareAlike 3.0 License, which allows others to remix, tweak, and build upon the work non-commercially, as long as the author is credited and the new creations are licensed under the identical terms.

For reprints contact: reprints@medknow.com

How to cite this article: Bajaj N, Monga P, Mahajan P. Assessment of consistency in the dimension of gutta-percha cones of ProTaper Next and WaveOne with their corresponding number files. Eur J Dent 2017;11:201-5.

DOI: 10.4103/ejd.ejd_167_16 
Although in 1958, Ingle and Levine made the first attempt at standardization of GP cones, continuous lack of standardization has been reported in many studies. ${ }^{[5,6]}$ Variations in tip diameter of master cone from master apical file tip diameter causes difficulty in fitting GP cone at working length, thus causing delay and frustration. These ill-fitting master cones can lead to premature binding or extension of cone beyond apex, thus leading to poor adaptability to canal walls. ${ }^{[4]}$

Variations in diameter of GP cones and their corresponding instrument have been studied by various authors. ${ }^{[7,8]}$ Salles et al. in 2013 showed significant differences in diameter of Mtwo system GP cone when compared with their corresponding instrument. ${ }^{[9]}$

Hence, in this study, we choose two contemporary single file systems available in market. First is WaveOne nickel-titanium (NiTi) file system from Dentsply Maillefer, Ballaigues, Switzerland, which is a single use, single file system to shape the root canal completely from start to finish. Second is the ProTaper Next system comprising five instruments, but most of the canals can be prepared using only the first two files of this system. Both systems come with GP cones having size corresponding to the last file used at working length.

There is not much literature reporting on the standardization of the dimensions of GP cone of WaveOne and ProTaper Next. Therefore, the present study aimed at comparing the dimensions of GP cones of ProTaper Next (25/0.06) and WaveOne (25/0.08) in relation to their corresponding instruments of the same dimension, respectively.

\section{MATERIALS AND METHODS}

A total of fifty GP cones were used for the study. These were divided into two groups of 25 samples each.

Group 1 consisted of 25 GP cones \# 25/0.06 (ProTaper Next) each from Lot No. 8222170F.

Group 2 consisted of 25 GP cones \# 25/0.08 (WaveOne) each from Lot No. 719915E.

To measure the GP points and instruments, a gauge ruler (Dentsply Maillefer) was used. To match the measuring canal of gauge ruler and metallic millimeter ruler (Camel), both were placed on flat glass slab. There were chances of displacement during the measurements, so utility wax (Hiflex, Prevest DenPro, India) was used to fix them on glass slab. Measuring site was marked with the aid of fine tip marker pen (Luxor). Diameter measurements at various sites were previously marked at GP cone and instrument was done with the aid of a digital caliper (Precise). Diameter of GP cones of both the groups was compared with their corresponding instruments: X2 ProTaper Next $(25 / 0.06)$ and WaveOne (25/0.08), respectively.

Measurements were done at D1 (1 mm short of the tip), D3 (3 $\mathrm{mm}$ short of the tip), and D11 (11 mm short of the tip) for GP cones of both groups and their corresponding instruments.

Single examiner recorded the readings twice and then those readings were put to statistical analysis.

\section{RESULTS}

For fifty GP cones, measurements were done twice by a single examiner for each marked site. Mean of the first and second measurements was put to statistical analysis, and then the standard deviation was obtained. Student's paired $t$-test was applied on the recorded data at $5 \%$ level of significance. No statistically significant difference was found between two measurements taken for ProTaper Next GP and WaveOne GP [Tables 1a and b]. The mean and standard deviation of the diameter of GP cones at each site (D1, D3, and D11) were calculated [Tables 2a and b]. Data were further assessed to compare the diameter of GP cones with their corresponding instruments [Tables $3 a$ and $b]$. Based on the results, it could be concluded that there was variation in the diameter of the GP cones, i.e., they do not correspond to the diameter of corresponding instrument.

\begin{tabular}{|c|c|c|c|c|c|}
\hline \multirow[t]{2}{*}{ Comparison } & \multirow[t]{2}{*}{$n$} & \multirow[t]{2}{*}{ Mean } & \multirow[t]{2}{*}{ SD } & \multicolumn{2}{|c|}{ Comparison } \\
\hline & & & & Paired $t$ & $P$ \\
\hline \multicolumn{6}{|l|}{ D1 } \\
\hline First measurement & 25 & 0.3188 & 0.02651 & 0.181 & 0.858 \\
\hline Second measurement & & 0.3180 & 0.02291 & & \\
\hline \multicolumn{6}{|l|}{ D3 } \\
\hline First measurement & 25 & 0.4396 & 0.02865 & 0.083 & 0.934 \\
\hline Second measurement & & 0.4392 & 0.01730 & & \\
\hline \multicolumn{6}{|l|}{ D11 } \\
\hline First measurement & 25 & 0.8804 & 0.02423 & 0.976 & 0.339 \\
\hline Second measurement & & 0.8752 & 0.02632 & & \\
\hline SD: Standard deviation & & & & & \\
\hline
\end{tabular}


In case of ProTaper Next (Group 1) at levels D1, D3, and D11, 25/0.06 GP points showed greater diameters than those of the corresponding instrument, which was statistically significant. However, in case of WaveOne (Group 2) at levels D3 and D11 size, 25/0.08 GP points showed greater diameters than those of the corresponding instrument which was statistically significant whereas it was nonsignificant at level D1.

\section{DISCUSSION}

For root canal treatment, rotary NiTi files are preferred over stainless steel files nowadays. ${ }^{[10]}$ Apart from having an advantage of being flexible, they come in greater taper as compared to $2 \%$ taper of stainless steel files. Matching their greater taper, corresponding taper GP cones are available for obturation. ${ }^{[9]}$ File systems such as WaveOne and ProTaper Next use single file or minimal files for whole canal preparation, thus giving shape to canal similar to the size and taper of their last instrument used at working length. Then, obturation of these canals is done by single GP cone corresponding to size of the last file used for canal preparation. If there is lack of compatibility

\begin{tabular}{|c|c|c|c|c|c|}
\hline \multicolumn{6}{|c|}{$\begin{array}{l}\text { Table 1b: Analysis of the reliability of the } \\
\text { measurements: Study error (Group } 2 \text { - WaveOne) }\end{array}$} \\
\hline \multirow[t]{2}{*}{ Comparison } & \multirow[t]{2}{*}{$n$} & \multirow[t]{2}{*}{ Mean } & \multirow[t]{2}{*}{ SD } & \multicolumn{2}{|c|}{ Comparison } \\
\hline & & & & Paired $t$ & $P$ \\
\hline \multicolumn{6}{|l|}{ D1 } \\
\hline First measurement & 25 & 0.2852 & 0.03441 & 1.072 & 0.294 \\
\hline Second measurement & & 0.2944 & 0.03536 & & \\
\hline \multicolumn{6}{|l|}{ D3 } \\
\hline First measurement & 25 & 0.4276 & 0.03166 & 0.345 & 0.733 \\
\hline Second measurement & & 0.4252 & 0.02293 & & \\
\hline \multicolumn{6}{|l|}{ D11 } \\
\hline First measurement & 25 & 0.8996 & 0.02731 & 0.072 & 0.943 \\
\hline Second measurement & & 0.8992 & 0.02707 & & \\
\hline
\end{tabular}

between GP cone and the corresponding instrument, obturation will not be adequate. Such inadequate obturation is the main cause for the root canal therapy failure. About $60 \%$ of root canal failures occur due to incomplete obturations. ${ }^{[11]}$ Therefore, the goal of obturation is to provide an impermeable fluid tight seal within the entire root canal system, to prevent oral and apical microleakage. ${ }^{[1,12]}$ To achieve this goal, size variation between GP cones and instrument should be avoided.

This requires that GP cones used for obturation should be standardized and closely match the last instrument used at working length. Currently, the American and ISO are two organizations which standardize the GP cones.

GP to be used as master cone should have its D1 tip diameter as close as possible to the diameter of instrument at corresponding position as this part of instrument is used for constructing the apical stop. ${ }^{[13]}$ This size compatibility between the diameter of the GP cone and the instrument will promote a proper fitting of master cone. ${ }^{[9]}$

According to the current standards, the accepted diameter of GP cone may vary from 0.005 to $0.007 \mathrm{~mm}$, as followed by most of reputed companies. Such variation means that cone of one stated size can be one size above and/or below, for example, ISO \# 25 cone can have ISO \# 30 or ISO \# 20.

Caliper used for measuring GP cone was placed perpendicular to the points of measurement at each GP cone, so it was possible to measure the greatest diameter. ${ }^{[13]}$ Due to flexible nature of GP cones and chances of dimensional change with change in temperature, there might be variation in diameter measurement. Further, measuring diameter of

\begin{tabular}{lcccccc}
\multicolumn{6}{l}{ Table 2a: Descriptive statistical analysis: Gutta-percha cone diameter (Group 1 - ProTaper Next) } \\
\hline Measurement & Size & $\boldsymbol{n}$ & Minimum & Maximum & Mean & SD \\
\hline D1 & $25 / 0.06$ & 25 & 0.27 & 0.37 & 0.3184 & 0.0222 \\
D3 & $25 / 0.06$ & 25 & 0.41 & 0.48 & 0.4394 \\
D11 & $25 / 0.06$ & 25 & 0.84 & 0.92 & 0.8778 & 0.0215 \\
\hline SD: Standard deviation & & & &
\end{tabular}

\begin{tabular}{lcccccc}
\multicolumn{5}{l}{ Table 2b: Descriptive statistical analysis: Gutta-percha cone diameter (Group 2 - WaveOne) } \\
\hline Measurement & Size & $\boldsymbol{n}$ & Minimum & Maximum & Mean & SD \\
\hline D1 & $25 / 0.08$ & 25 & 0.23 & 0.35 & 0.2898 \\
D3 & $25 / 0.08$ & 25 & 0.40 & 0.47 & 0.4264 \\
D11 & $25 / 0.08$ & 25 & 0.85 & 0.94 & 0.0215 \\
\hline
\end{tabular}

SD: Standard deviation 


\begin{tabular}{|c|c|c|c|c|c|}
\hline Diameter & Group & $n$ & Mean & SD & $P$ \\
\hline \multirow[t]{2}{*}{$\mathrm{D} 1$} & GP & 25 & 0.3184 & 0.02216 & $<0.001$ \\
\hline & Instrument & 6 & 0.2483 & 0.01126 & \\
\hline \multirow[t]{2}{*}{ D3 } & GP & 25 & 0.4394 & 0.02038 & $<0.001$ \\
\hline & Instrument & 6 & 0.3692 & 0.01828 & \\
\hline \multirow[t]{2}{*}{ D11 } & GP & 25 & 0.8778 & 0.02151 & $<0.001$ \\
\hline & Instrument & 6 & 0.6392 & 0.08145 & \\
\hline
\end{tabular}

SD: Standard deviation, GP: Gutta-percha

\begin{tabular}{|c|c|c|c|c|c|}
\hline Diameter & Group & $n$ & Mean & SD & $P$ \\
\hline \multirow[t]{2}{*}{ D1 } & GP & 25 & 0.2898 & 0.02752 & 0.818 \\
\hline & Instrument & 6 & 0.2925 & 0.01255 & \\
\hline \multirow[t]{2}{*}{ D3 } & GP & 25 & 0.4264 & 0.02148 & $<0.001$ \\
\hline & Instrument & 6 & 0.4825 & 0.01754 & \\
\hline \multirow[t]{2}{*}{ D11 } & GP & 25 & 0.8994 & 0.02342 & $<0.001$ \\
\hline & Instrument & 6 & 0.7800 & 0.02168 & \\
\hline
\end{tabular}

SD: Standard deviation, GP: Gutta-percha

these types of materials with metal digital caliper is extremely difficult as slight change in pressure can alter the size. Aguiar et al. also used the digital caliper for measurements in their study. ${ }^{[14]}$

Experienced endodontist can cope up with diameter and tip size variability while choosing a master cone, but this ty pe of discrepancy can be a nagging problem for inexperienced clinician, resulting in wastage of time. There are also concerns about fit of GP along the entire length of root canal from apical to coronal third as any discrepancy can lead to leakage. These mismatching cones can further result in either over or under obturations, thus causing treatment failure in the long run. In these situations, clinician may either have to cut the tip of GP cones by using GP gauge or use a smaller size GP cones arbitrarily.

However, there is also a concern with the GP gauge that it might not accurately cut larger taper GP cones to the correct tip size because the instrument is designed for use with 0.02 taper cones only.

Kunert et al. in 2008 measured adaptation of F1, F2, and F3 GP points at D0 using different gauze rulers. ${ }^{[15]}$ However, no measuring ruler assessed the adaptation of the GP point and corresponding rotary files adequately. This study presumed that WaveOne or ProTaper Next instruments shaped the dentinal walls of root canals to their corresponding shape. However, no consideration was given to the canals shape variations that are frequently present, for example, oval canals. These canal shape variations make it necessary to fill the left out spaces with lateral condensation methods or sealer. Shortcomings of sealers should also have been taken into consideration.

\section{CONCLUSION}

In the present study, it was found that the diameters of both the ProTaper Next and WaveOne GP cones were greater than their corresponding instruments. Hence, there are chances of under obturation with both systems. In Group 2, diameter was matching at D1 only, but larger diameter of WaveOne GP cone at D3, D11 can lead to taper lock as well as inadequate adaptation near apical stop. Further research is needed in this area to apply these findings clinically.

\section{Acknowledgments}

We would like to thank Genesis Institute of Dental Sciences and Research for allowing and giving ethical clearance to conduct the study.

\section{Financial support and sponsorship}

Nil.

\section{Conflicts of interest}

There are no conflicts of interest.

\section{REFERENCES}

1. Schilder H. Filling root canals in three dimensions 1967. J Endod 2006;32:281-90.

2. Wu MK, van der Sluis LW, Wesselink PR. A preliminary study of the percentage of gutta-percha-filled area in the apical canal filled with vertically compacted warm gutta-percha. Int Endod J 2002;35:527-35.

3. Desai S, Chandler N. Calcium hydroxide-based root canal sealers: A review. J Endod 2009;35:475-80.

4. Cunningham KP, Walker MP, Kulild JC, Lask JT. Variability of the diameter and taper of size \#30, 0.04 gutta-percha cones. J Endod 2006;32:1081-4.

5. Hartwell GR, Barbieri SJ, Gerard SE, Gunsolley JC. Evaluation of size variation between endodontic finger spreaders and accessory gutta-percha cones. J Endod 1991;17:8-11.

6. Zinelis S, Magnissalis EA, Margelos J, Lambrianidis T. Clinical relevance of standardization of endodontic files dimensions according to the ISO 3630-1 specification. J Endod 2002;28:367-70.

7. Goldberg F, Massone EJ, Pruskin E, Zmener O. SEM study of surface architecture of gutta-percha cones. Endod Dent Traumatol 1991;7:15-8.

8. Moule AJ, Kellaway R, Clarkson R, Rowell J, Macfarlane R, Lewis D, et al. Variability of master gutta-percha cones. Aust Endod J 2002;28:38-43.

9. Salles AA, Cord CB, Sonnemann TS, De Melo TA, Irala LE, De Oliveira EP. Comparative analysis of the diameter of MTwo system gutta-percha points in relation to their corresponding instruments. Rev Sul Brazileira Odontol 2013;10:49-55 
10. Kim KW, Cho KM, Park SH, Choi KY, Karabucak B, Kim JW. A comparison of dimensional standard of several nickel-titanium rotary files. Restor Dent Endod 2014;39:7-11.

11. Saatchi M, Barekatain B, Behzadian M. Comparing the apical microleakage of lateral condensation and chloroform dip techniques with a new obturation method. Dent Res J (Isfahan) 2011;8:22-7.

12. Zanoni EM, Leonardo MR, Lia RC, Tagliavini RL.Empty spaces in endodontic fillings. Rev Gaucha Odontol 1998;36:232-9.
13. Waechter F, Antunes RO, Irala LE, Limongi O. Comparative evaluation between the diameter of standardized cones and secondary cones B8 calibrated by calibration scale, measuring $1 \mathrm{~mm}$ from its tips (D1) Rev Sul Brazileira Odontol 2009;6:34-43.

14. Aguiar CM, Cavalcanti JS, Coelho KC. Sealing apical post treatment endodontic. Rev Gaucha Odontol 2004;53:281-4.

15. Kunert GK, Melo TA, Oliveira EP, Barletta FB. Accuracy of the tip diameter on gutta-percha cones of different tapers. Rev Assoc Cir Dent 2008;62:309-13. 